\title{
AVALIAÇÃO DA CERÂMICA VERMELHA DE ROSÁRIO (MA) A PARTIR DA ADIÇÃO DE FINO DE ROCHAS ORNAMENTAIS
}

David Guilhon

Programa de Pós-graduação em Design, Universidade Federal do Maranhão

dvdguilhon@gmail.com

Denilson Moreira dos Santos

Programa de Pós-graduação em Design, Universidade Federal do Maranhão denilson.santos@ufma.br

Jamerson Araújo Farias

Programa de Pós-graduação em Design, Universidade Federal do Maranhão Jamerson.far@gmail.com

Resumo: $O$ presente trabalho avalia a adição de resíduos de rochas ornamentais nas propriedades tecnológicas da cerâmica vermelha de Rosário (MA), agregando benefícios ambientais, econômicos, funcionais e tecnológicos. Para tanto, procedeu-se a elaboração de diferentes composições, as quais foram queimadas a diferentes temperaturas. Os resultados revelam que temperatura de queima acima de $1050^{\circ} \mathrm{C}$ e o aumento de resíduos contribuem para o ganho de resistência do material e redução de defeitos neste. As composições que apresentaram melhor desempenho foram as $15 \%, 10 \%$ e $20 \%$, todas sinterizadas a $1100^{\circ} \mathrm{C}$, na ordem decrescente. Sendo assim, as características deste material afirmam a viabilidade deste na fabricação de revestimento de paredes, objetos planos e utilitários domésticos.

Palavras-chave: Design, cerâmica vermelha, rochas ornamentais.

Abstract: This paper evaluates the addition of waste of ornamental rocks in the technological properties of red ceramic of Rosário (MA), adding environmental, economical, functional and technological benefits. Therefore, it proceeded to the development of different compositions, which were fired at different temperatures. Results show that firing temperature above $1050^{\circ} \mathrm{C}$ and increase of percentage of wastes contribute to gain of material resistance and its defects reduction. Therefore, compositions appearances better performance was 15\%, 10\% and 20\%, all from $1100^{\circ} \mathrm{C}$ series, in decrease order. Thus, the material characteristics affirms its viability to use in flat objects, domestics utilities and decorating's.

Keywords: Design, red ceramic, dimensional stones. 


\section{INTRODUÇÃO}

Atualmente para as indústrias o maior desafio é conciliar viabilidade econômica com a viabilidade ecológica, favorecendo a redução de custos para estas duas ordens.

A cerâmica vermelha, também conhecida por estrutural, é assim chamada por conta da cor avermelhada que seus produtos possuem e por ser empregada na construção civil, como afirmam Motta, Zanardo e Cabral Junior (2001). Com isso, Santos (1989) afirma que tal indústria apresenta como matéria-prima principal para seus produtos (tijolos, telhas, lajotas, ladrilhos, tubos cerâmicos e outros) a argila. Tal material se apresenta na natureza em abundância, além de possuir características de plasticidade, resistência mecânica a verde e após a queima, bem como a as múltiplas possibilidades de conformação (PUREZA, 2004).

Diante de tantas qualidades que a cerâmica vermelha possui, Dantas (2008) fala que a utilização dos resíduos de rochas ornamentais na indústria ceramista tem sido uma maneira definitiva para a retirada deste do meio ambiente, de modo que a não mais poluir rios, mares e solo quando acumulados. Aponta, ainda, que a incorporação destes rejeitos pode trazer vantagens adicionais na melhoria do processo e nas características dos produtos obtidos.

Esta pesquisa visa confrontar características visuais do material com suas propriedades tecnológicas, verificando a viabilidade técnica da adição dos resíduos trabalhados.

\section{MÉTODOS E TÉCNICAS}

O compósito desenvolvido nesta pesquisa foi obtido pela adição de fino de rochas de granito e mármore, coletados em marmorarias de São Luís, à massa cerâmica vermelha, oriunda do município de Rosário (MA). O preparo desse material usou apenas $10 \%$ de água para a conformação dos corpos de prova (CP's) em molde metálico.

Trabalharam-se os seguintes percentuais de resíduos em relação à composição total das amostras: $0 \%, 10 \%, 15 \%, 20 \%$ e $25 \%$ em peso. Para cada qual foram confeccionados 3 corpos de prova. Também como variável de análise, foram realizadas 3 queimas em temperaturas diferentes $\left(900^{\circ} \mathrm{C}, 1000^{\circ} \mathrm{C}\right.$ e $\left.1100^{\circ} \mathrm{C}\right)$. Perfazendo-se 45 corpos de provas, sendo 15 de cada temperatura, destes 12 possuem os resíduos de rochas ornamentais e 3 puras.

Os corpos de prova, após conformados por prensagem mecânica a $20 \mathrm{MPa}$, passaram pelo processo de secagem durante 4 dias ao ar livre e $24 \mathrm{~h}$ em estufa elétrica, a $110^{\circ} \mathrm{C}$. Depois, foram sinterizados, sendo que as temperaturas possuem em comum a temperatura inicial de queima $\left(30^{\circ} \mathrm{C}\right)$, duração de $4 \mathrm{~h}$ de patamar de queima e taxa de aquecimento $\left(3^{\circ} \mathrm{C} / \mathrm{min}\right)$.

As massas e dimensões dos corpos de provas foram identificadas em cada etapa (conformação, secagem e queima). Ademais, identificaram-se após a queima as massas imersas e úmidas, quando por $24 \mathrm{~h}$ as peças ficaram imersas em água.

Estes importantes dados possibilitaram a análise das propriedades tecnológicas do material, por meio da aplicação das equações apresentadas a seguir.

E, finalmente, foi realizada a análise visual dos CP's, que será confrontada com os dados das propriedades tecnológicas. 


\subsection{Propriedades tecnológicas}

As propriedades tecnológicas do material oferecem subsídios para delinear a composição ideal para a confeç̧ão de produtos: absorção de água, porosidade aparente, densidade aparente e retração linear após secagem e após a queima. Para tanto, fez-se uso das seguintes:

\subsubsection{Absorção de água}

Tal propriedade corresponde à capacidade de o material absorver água (GUIMARÃES, 2015). Para tanto, utilizou-se como referência para este estudo o Método de Arquimedes de imersão para obter-se as massas, sendo aplicadas em seguida na equação 1:

Onde:

$$
A A=(m u-m s) /(m u) \times 100
$$

AA = Absorção da água (\%); ms = Massa seca (g); mu = Massa úmida, após a imersão (g)

\subsubsection{Porosidade aparente}

Para Askeland e Wright (2014), tal propriedade consiste na quantidade de poros interconectados que determina a permeabilidade ou a facilidade com que os fluidos escoam através da peça cerâmica porosa. Identifica-se a massa do corpo de prova quando seco e, em seguida, quando úmido. Esta segunda é consoante o procedimento de imersão usado para a absorção de água. Procedeu-se a equação 2:

Onde:

$$
\mathrm{PA}=(\mathrm{mu}-\mathrm{ms}) /(\mathrm{mu}-\mathrm{mi}) \times 100
$$

$\mathrm{PA}=$ Porosidade aparente (\%); $\mathrm{mu}=$ Massa úmida (g); $\mathrm{ms}=$ Massa seca (g); $\mathrm{mi}=$ Massa imersa (g)

\subsubsection{Densidade aparente}

É a determinação da massa de material em um dado volume ocupado pela mesma, como quer Guimarães (2015). O procedimento para este ensaio é fruto da norma ASTM C373-88 (2006), que expressa a razão entre a massa e o volume dos corpos após a sinterização, representada pela equação 3:

Onde:

$$
\mathrm{DA}=\mathrm{mq} / \mathrm{vq}
$$

$\mathrm{DA}=$ Densidade aparente $\left(\mathrm{g} / \mathrm{cm}^{3}\right) ; \mathrm{mq}=$ Massa pós-queima $(\mathrm{g}) ; \mathrm{vq}=$ Volume pós-queima $\left(\mathrm{cm}^{3}\right)$

\subsubsection{Retração linear}

Esta propriedade verifica a redução em uma das dimensões por influência da perda de água e matéria orgânica. Possui duas situações de comparação de retração: após secagem e após queima. Para a primeira, relaciona-se o comprimento da peça conformada com tal dimensão mensurada após a secagem. Já a segunda é a relação do comprimento da peça queimada com a mesma dimensão da peça seca. Para Gouveia (2006), essa propriedade é importante para o projeto do molde, pois auxilia na percepção de deformidades excessivas que possam inviabilizar o uso da peça cerâmica, sendo, conforme Tallini Junior (2009), um relevante requisito industrial. As equações 4 e 5 expressam essas pontes: 


$$
\mathrm{RLS}=(\mathrm{Ic}-\mathrm{Is}) /(\mathrm{Is}) \times 100
$$

Onde:

RLs = Retração linear pós-secagem (\%); lc = Comprimento do corpo de prova conformado (mm); Is = Comprimento do corpo de prova seco $(\mathrm{mm})$

Onde:

$$
\mathrm{RLq}=(\mathrm{Is}-\mathrm{lq}) /(\mathrm{Is}) \times 100
$$

RLq = Retração linear pós-queima (\%); Is = Comprimento do corpo de prova seco $(\mathrm{mm})$; $\mathrm{lq}=$ Comprimento do corpo de prova queimado $(\mathrm{mm})$

\subsection{Análise visual}

Foi efetuada em conformidade com da ABNT NBR 13.818:1997, com as devidas adaptações sugeridas por Guimarães (2015), onde criou-se um check list com base na identificação da presença de defeitos visíveis a olho nu nas amostras. Também se efetuou a caracterização cromática destas peças por meio da análise das tonalidades de cor via fotografia. Os defeitos a serem analisados e contabilizados são: rachaduras, depressões, crateras, bolhas, furos, manchas, cantos e lados lascados, saliências, incrustações de corpos estranhos, riscados ou arranhaduras e diferença de tonalidade.

\section{RESULTADOS OBTIDOS E DISCUSSÕES}

Todos os 45 CP's foram confeccionados em um mesmo molde metálico. Após a conformação, passaram pela secagem ao ar livre durante 4 dias e em estufa por $24 \mathrm{~h}$ a $110^{\circ} \mathrm{C}$. Sendo, então, queimados em 3 temperaturas diferentes $\left(900^{\circ} \mathrm{C}, 1000^{\circ} \mathrm{C}\right.$ e $1100^{\circ} \mathrm{C}$ ) em forno elétrico.

A Tabela 1 mostra todos os valores encontrados, frutos das equações matemáticas efetuadas com as dimensões e massas obtidas de cada composição. Com estes valores, plotaram-se gráficos para interpretação e análise de cada uma das propriedades tecnológicas descritas nesta pesquisa.

\begin{tabular}{|c|c|c|c|c|c|c|c|c|c|c|c|c|c|c|}
\hline \multicolumn{15}{|c|}{ MEDIÇÃO E PESAGEM DOS CORPOS DE PROVA } \\
\hline Código & \multicolumn{4}{|c|}{ Após a conformação } & \multicolumn{4}{|c|}{ Após a secagem } & \multicolumn{4}{|c|}{ Após a sinterização } & \multicolumn{2}{|c|}{ Outras massas } \\
\hline A900 & 79,88 & 42,00 & 11,55 & 71,03 & 78,77 & 41,47 & 11,62 & 62,93 & 78,62 & 41,27 & 11,58 & 59,27 & 49,83 & 72,32 \\
\hline B900 & 80,00 & 42,07 & 12,40 & 74,53 & 79,25 & 41,82 & 12,28 & 66,20 & 78,93 & 41,55 & 12,42 & 62,27 & 34,29 & 77,52 \\
\hline D900 & 79,72 & 41,98 & 13,32 & 72,80 & 79,28 & 41,67 & 13,27 & 67,20 & 79,08 & 42,08 & 13,20 & 63,00 & 51,74 & 80,22 \\
\hline E900 & 79,87 & 41,98 & 13,10 & 72,77 & 79,23 & 41,70 & 13,05 & 67,77 & 79,08 & 41,62 & 12,73 & 63,07 & 51,53 & 80,12 \\
\hline A1000 & 79,78 & 41,97 & 12,67 & 70,50 & 79,23 & 41,70 & 12,52 & 64,74 & 78,47 & 41,05 & 12,38 & 61,13 & 33,02 & 75,05 \\
\hline E1000 & 79,48 & 42,12 & 14,12 & 75,83 & 79,38 & 41,58 & 14,23 & 70,51 & 78,53 & 41,47 & 13,93 & 66,00 & 36,10 & 83,80 \\
\hline A1100 & 78,10 & 73,50 & 15,50 & 78,10 & 79,40 & 41,83 & 15,30 & 73,50 & 75,98 & 40,03 & 14,62 & 69,20 & 55,63 & 84,44 \\
\hline
\end{tabular}

Tabela 1 - Dimensões e massas dos corpos de prova 


\begin{tabular}{lllllllllllllll}
\hline B1100 & 77,89 & 73,44 & 15,22 & 77,89 & 79,40 & 42,02 & 15,13 & 73,44 & 75,38 & 39,83 & 14,32 & 69,11 & 55,02 & 82,69 \\
\hline C1100 & 77,79 & 73,42 & 15,40 & 77,79 & 79,38 & 41,98 & 15,28 & 73,42 & 74,30 & 39,28 & 14,33 & 69,01 & 55,34 & 81,53 \\
\hline D1100 & 74,16 & 69,38 & 14,35 & 74,16 & 79,25 & 41,87 & 14,22 & 69,38 & 74,48 & 39,53 & 13,12 & 64,42 & 52,20 & 77,33 \\
\hline E1100 & 75,90 & 70,92 & 14,73 & 75,90 & 79,25 & 41,95 & 14,58 & 70,92 & 75,18 & 39,92 & 13,88 & 66,52 & 52,92 & 79,58 \\
\hline
\end{tabular}

Fonte: Elaborado pelo autor, com base na pesquisa realizada

\subsection{Propriedades tecnológicas}

\subsubsection{Absorção de água (AA)}

A Figura 1 ilustra o comportamento da absorção de água de todos os corpos de prova para diferentes temperaturas.

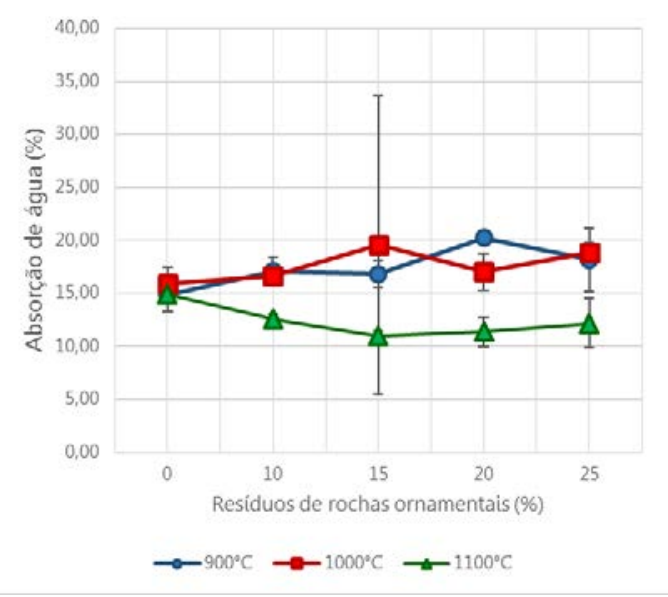

Figura 1 - Gráfico de absorção de água das composições de três séries de cerâmica vermelha.

A absorção de água exerce influência em outras propriedades, como a resistência mecânica à flexão, como defendem Souza, Souza e Rolim Filho (2008). Assim, a relação entre estas duas propriedades é inversamente proporcional, ou seja, quanto menor for o índice de absorção de água, mais resistente será a cerâmica.

Logo, trata-se de um indicativo de que as composições com resíduos da série $1100^{\circ} \mathrm{C}$ possuem resistência mecânica maior que a sua amostragem pura e que as outras duas séries analisadas $\left(900^{\circ} \mathrm{C}\right.$ e $\left.1000^{\circ} \mathrm{C}\right)$. Sendo assim, consideraram-se as composições $15 \%, 20 \%$ e $25 \%$ em peso da série $1100^{\circ} \mathrm{C}$, por apresentarem os melhores resultados, quanto à absorção de água.

A norma NBR 13.818:1997 (ABNT, 1997) fala que corpos cerâmicos que apresentam valores acima de $10 \%$ são classificados como porosos. Logo, todas as composições das 3 séries são porosas, podendo ser empregados como revestimento de paredes, por conta da sua alta absorção e baixa resistência mecânica, conforme este mesmo critério e o Inmetro.

\subsubsection{Porosidade aparente (PA)}

Os resultados do comportamento dos corpos de prova em relação à porosidade estão representados no gráfico da Figura 2. 


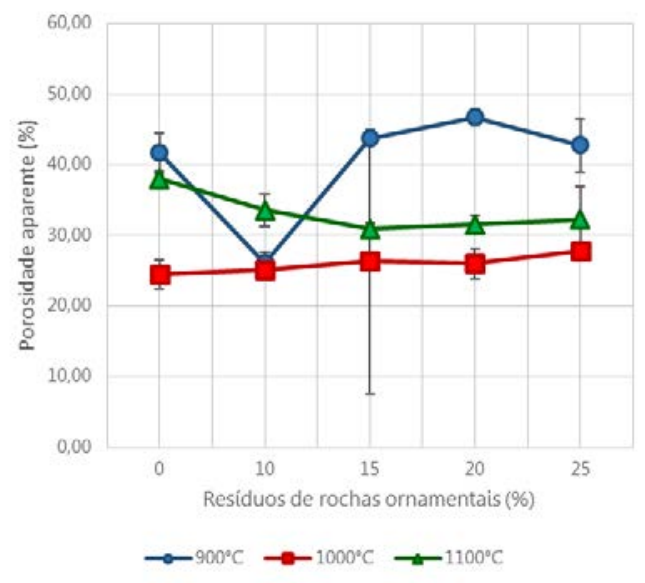

Figura 2 - Gráfico de porosidade aparente das composições de três séries de cerâmica vermelha.

Askeland e Wright (2014) falam que a porosidade apresenta influências positivas ou negativas sobre o material. Assim, tal índice pode indicar a facilidade do surgimento de trincas, conferindo fragilidade à peça ou o contrário: resistência ao choque térmico. É necessário dizer que este trabalho não tem como foco a resistência ao choque. Logo, priorizam-se amostras com índices de porosidade menor possível, portanto, corpos mais resistentes.

As cerâmicas que apresentaram os resultados mais satisfatório quanto à porosidade aparente foram as com $10 \%$ e $20 \%$ em peso da série $1000^{\circ} \mathrm{C}$ e a com $10 \%$ em peso da série $900^{\circ} \mathrm{C}$.

\subsubsection{Densidade aparente (DA)}

Para Oliveira (2000), uma densidade elevada, acima de 2,1 e $2,2 \mathrm{~g} / \mathrm{cm}^{3}$, pode resultar em trincas e bolhas nas peças cerâmicas. Isto se dá por conta da dificuldade de se eliminar os gases existentes no interior das peças durante a queima. Logo, todas as amostragens se enquadram dentro desse parâmetro, como mostra o gráfico da Figura 3.

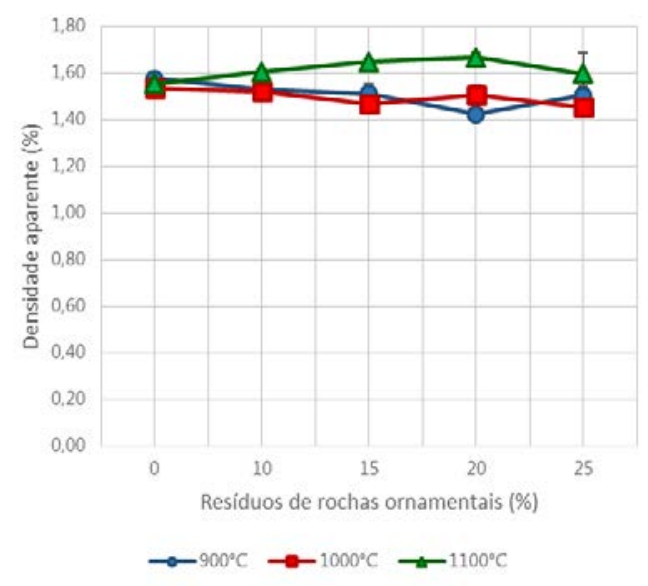

Figura 3 - Gráfico de densidade aparente das composições de três séries de cerâmica vermelha. 
Quanto maior o índice da amostragem, maior é sua densidade. E esta propriedade é inversamente proporcional à porosidade, como quer Jung et al (2012). Isso acaba se estendendo para a resistência mecânica, que é inversamente proporcional à porosidade, logo, diretamente proporcional à densidade, complementa Guimarães (2015). Por este pensamento, é desejável que a cerâmica possua menos poros, para que assim, tenha maiores resistência mecânica e densidade.

Deste modo, as cerâmicas confeccionadas para a série $1100^{\circ} \mathrm{C}$ com $20 \%, 15 \%$ e $10 \%$ em peso foram as que manifestaram melhores resultados quanto à densidade, nesta ordem.

\subsubsection{Retração linear}

Com relação à retração linear, foram efetuados dois tipos de ensaios diferentes: retração linear após a secagem (RLs) e após a queima (RLq).

\subsubsection{Retração linear após a secagem (RLs)}

Para a este tipo de retração linear, o gráfico da Figura 5 ilustra o comportamento dos corpos de prova, onde as diferenças dimensionais do comprimento foram percebidas entre a conformação e o final da secagem.

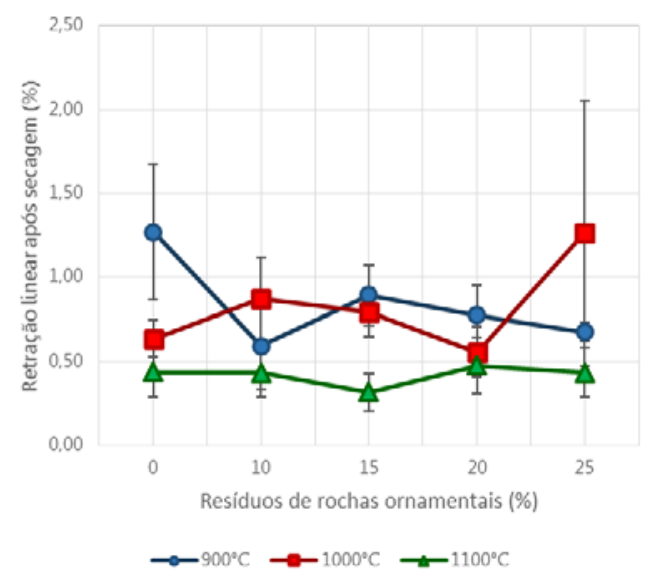

Figura 5 - Gráfico de retração linear após secagem das composições de três séries de cerâmica vermelha.

Durante a secagem, a perda dimensional é denunciada com a perda de água, onde o líquido em excesso evapora (GUIMARÃES, 2015). Consequentemente, objeto atinge estabilidade em sua forma e perde plasticidade. Para a Vieira, Feitosa e Monteiro (2003), a secagem é uma fase tão importante e capaz de gerar imperfeições nos produtos, que são percebidas apenas após a queima. Portanto, os resultados devem apresentar valores inferiores à referência pura e tender a estabilidade, reduzindo o surgimento de defeitos.

Diante disso, a série $1100^{\circ} \mathrm{C}$ apresenta as composições $15 \%, 10 \%$ e $25 \%$ em peso como os melhores resultados, quanto à RLs. 


\subsubsection{Retração linear após a queima (RLq)}

Este segundo momento de retração linear, o gráfico da Figura 6 demonstra o comportamento dos corpos de prova, cujas diferenças dimensionais do comprimento foram percebidas entre o final da secagem e o final da queima.

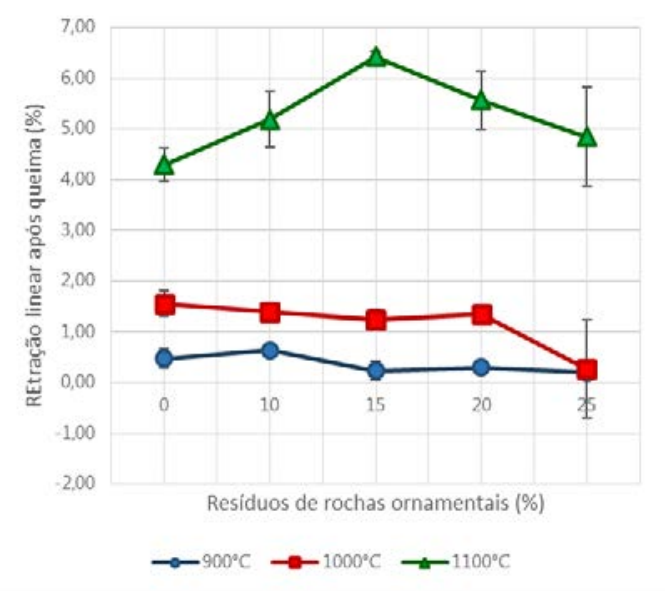

Figura 6 - Gráfico de retração linear após queima das composições de três séries de cerâmica vermelha.

Guimarães (2015) defende que a sinterização promove a redução dimensional por conta da diminuição dos espaços existentes entre as moléculas, havendo, pois, redução de poros. Portanto, a sua importância para se ter a previsão mais aproximada possível das dimensões finais dos produtos. Fora a busca do controle da qualidade das peças, este ensaio possibilita identificar composições que possuem maior probabilidade de surgimento de trincas e imperfeições, normalmente encontrados em corpos cerâmicos que tem elevados valores de RLq.

O índice de retração linear após a queima abaixo de $1 \%$ é apontado como o ideal para uso em revestimento, como afirma Oliveira (2000), possuindo máxima estabilidade dimensional durante a queima.

Pinheiro (2009) e de Prado (2014) comprovam, por meio de seus estudos, que a elevada temperatura contribui para a elevação da tensão de ruptura em experimentos onde se adiciona mármore e granito à cerâmica vermelha, sobretudo se queimados até $1050^{\circ} \mathrm{C}$. Tal resultado obtido na série $1100^{\circ} \mathrm{C}$ se aproxima aos dois estudos citados. Guimarães (2015) reforça a real influência da temperatura de queima sobre a propriedade do material, especialmente na sua resistência a esforços mecânicos, quando este é submetido à queima de $1150^{\circ} \mathrm{C}$ atinge uma marca entre $17 \mathrm{e}$ $23 \mathrm{Mpa}$. Logo, foi possível dizer que objetos sinterizados abaixo de $1050^{\circ} \mathrm{C}$ possuem baixa tensão.

As amostras que apresentam os resultados satisfatórios, quanto à retração linear após a queima, são $20 \%, 25 \%$ e $15 \%$ em peso, todas da série $900^{\circ} \mathrm{C}$. Vale frisar que em todas as amostras foram usadas o mesmo molde metálica para sua confecção. 


\subsection{Análise visual}

\subsubsection{Enumeração dos problemas superficiais}

A análise visual apresentou um total de 256 problemas, onde a maior incidência foram os 201 cantos e lados lascados, seguidos de 15 rachaduras, 11 depressões, 9 riscados ou arranhaduras, 9 crateras, 5 pintas e empatando em 2 quantidades de furos, machas e saliências. Por outro lado, não apresentaram bolhas e incrustações de corpos estranhos. Quanto à alta frequência de cantos lascados, relata-se que sua minimização pode ser possibilitada com um maior controle e cuidado na confecção das peças durante todo o processo produtivo. A média de defeitos encontrados para todo o experimento foi de 6,13.

O gráfico da Figura 7 evidenciam uma tendência de queda da quantidade de defeitos em cada uma das três temperaturas, sobretudo nas séries $1000^{\circ} \mathrm{C}$ e $1100^{\circ} \mathrm{C}$, sendo esta última com valores menores e mais próximos entre si.

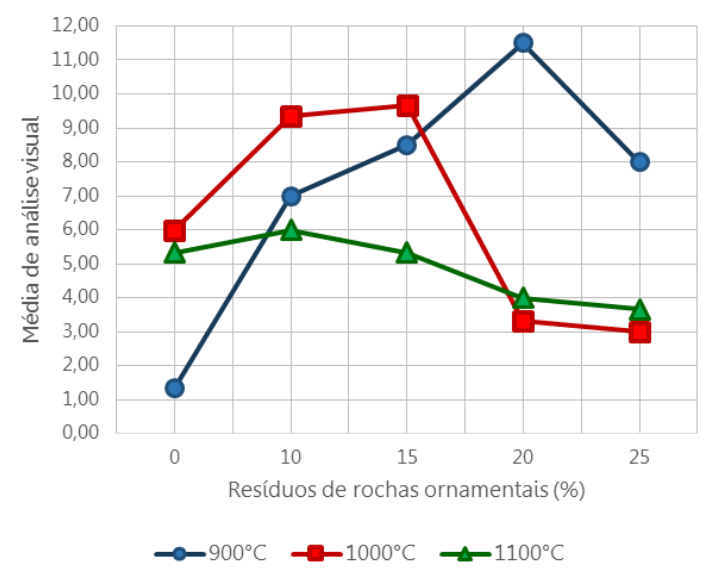

Figura 7 - Média dos valores obtidos por análise visual

Como já citado, Prado (2014) lembra que as peças sinterizadas à $1150^{\circ} \mathrm{C}$ atingem uma maior resistência mecânica. Guimarães (2015) reforça dizendo que quanto maior for a temperatura de queima, maior será a aglutinação das partículas e, por conseguinte, mais resistente e com melhor qualidade será o material. Sendo assim, é possível afirmar que à medida em que se aumentam o percentual de resíduos à cerâmica e a temperatura de queima, menor será a quantidade de imperfeições superficiais encontradas.

Por fim, os melhores resultados encontrados nesta avaliação, excluindo a amostra pura da série $900^{\circ} \mathrm{C}$ (média 1,33), foram: o percentual $25 \%$ em peso da série $1000^{\circ} \mathrm{C}$ (média 3,00 ), percentual $20 \%$ em peso da série $1000^{\circ} \mathrm{C}$ (média 3,33 ) e percentual $25 \%$ em peso da série $1100^{\circ} \mathrm{C}$ (média 3,67).

\subsubsection{Diferenças de tonalidade}

É relevante a observação desta característica, pois é importante prever-se a cor do material nas aplicações dos produtos. Desse modo, observou-se, ainda, que 30 dias após a queima, os CP's apresentaram nítida diferença em suas cores, sendo estas escurecidas com o passar do tempo, como ilustra a Figura 8. 


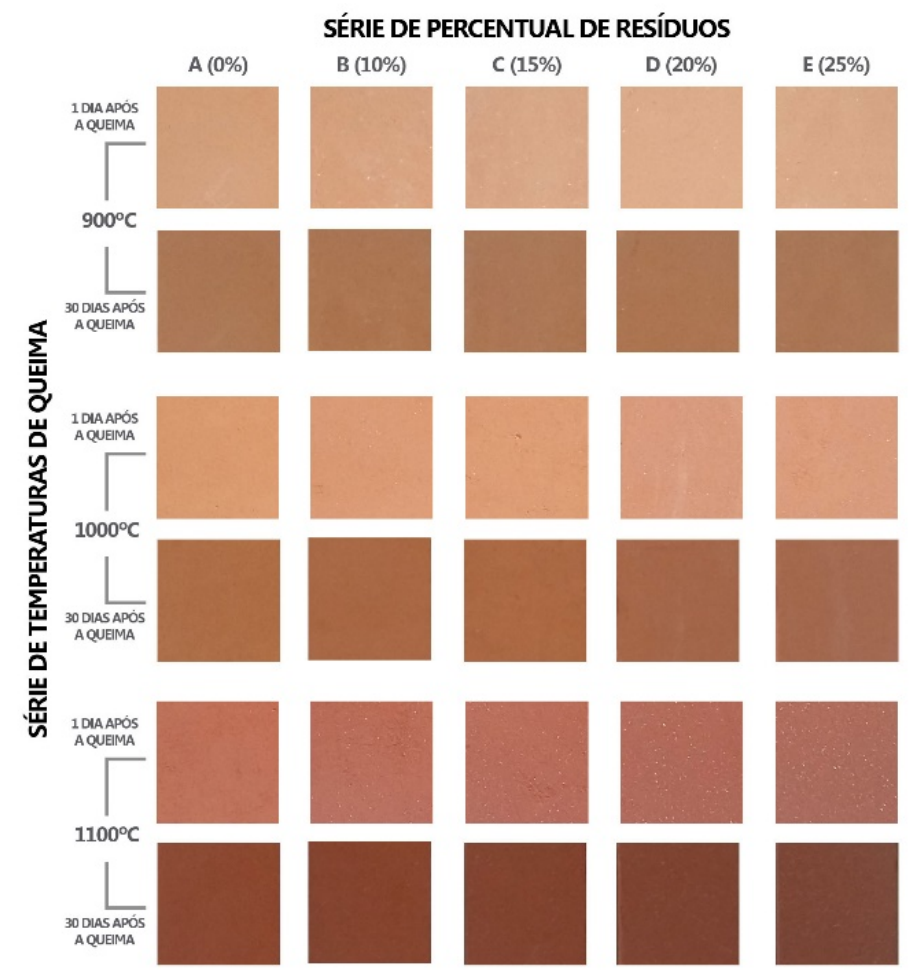

Figura 8 - Comparativo de tonalidades da cerâmica vermelha com adição de resíduos de granito e mármore, após um dia e trinta dias de queima

A série $900^{\circ} \mathrm{C}$ é a mais clara das três e apresenta coloração mais estável, mesmo com a sutil presença de manchas claras ao passo de que se aumenta a quantidade de resíduos. Tal estabilidade cromática foi basicamente percebida na série $1000^{\circ} \mathrm{C}$, porém a temperatura de queima realçou o tom avermelhado das peças. Já a série $1100^{\circ} \mathrm{C}$ apresentou tonalidade bem mais acentuada. A presença de resíduos ficou evidente na presença das manchas e no escurecimento gradativo das peças.

O escurecimento com o passar de 30 dias é notório, pois à medida em que mais resíduo foi adicionado, mais escuro o corpo cerâmico se tornou, tornando significativa a diferença entre as composições. É, ainda, perceptível que a temperatura de queima enaltece ainda mais essa variação. Levanta-se como hipótese para tal fenômeno que a presença de óxido de ferro favoreça tal coloração e que, talvez, exista outro componente mineral no fino de rochas que possa contribuir fortemente para este fenômeno (GUIMARÃES, 2015).

Entretanto, vale lembrar que as rochas que são cortadas nas marmorarias nem sempre são iguais, pois seu beneficiamento é feito sob demanda. O rejeito, acumulado em tanques, desse processo de corte pode ter suas cores variadas, além de não recebem tratamento térmico prévio. Contudo, o material não é desqualificado por conta disso, pois esta imprevisibilidade pode conferir um aspecto sutilmente rústico aos produtos.

\section{CONCLUSÃO}

A análise visual contabilizou as imperfeições das peças, onde os resultados obtidos apontam tendência a redução de defeitos com o aumento da temperatura de queima (média por temperatura), como também apresentaram redução do índice para 
a série $1100^{\circ} \mathrm{C}$ à proporção que se adiciona resíduo, porém nas séries $900^{\circ} \mathrm{C}$ e $1000^{\circ} \mathrm{C}$ esse índice tende a aumentar, salvo algumas quedas de valores.

Sendo assim, os testes de AA e PA mostraram que quanto mais resíduos adicionados, menor são estes índices, sobretudo para séries $1100^{\circ} \mathrm{C}(\mathrm{AA})$ e $1000^{\circ} \mathrm{C}$ (PA). Logo, a resistência tende a aumentar quando estes dois indicadores apontam quedas.

Os valores de DA se mantêm equilibrados em todas as amostras com resíduos nas 3 séries de temperaturas, sugerindo estabilidade no quesito resistência.

Nas RLs e RLq, a adição de resíduos promove a mesma tendência ao equilíbrio, mesmo com variações com efeito inverso em uma das séries na secagem $\left(900^{\circ} \mathrm{C}\right) \mathrm{e}$ acentuada oscilação depois da queima $\left(1100^{\circ} \mathrm{C}\right)$. De fato, há melhorias em suas propriedades, coisa evidenciada na menor ocorrência de trincas e outras falhas visíveis.

Verificou-se, ainda, que à medida que se adiciona resíduos à massa cerâmica, ocorre a redução da resistência mecânica nas séries de temperatura $900^{\circ} \mathrm{C}$ e $1000^{\circ} \mathrm{C} \mathrm{e}$ aumento dela na série $1100^{\circ} \mathrm{C}$, não apresentando exceção alguma.

Resumindo, a última série $\left(1100^{\circ} \mathrm{C}\right)$ é mais resistente que as outras duas e tende a apresentar menores valores de AA, PA e RLs, além de DA equilibrada. O que Ihe a esta série, além de ótimas características tecnológicas, boas propriedades visuais (menos falhas e defeitos visíveis).

Por fim, dentre todas as combinações, cruzando os cinco (5) percentuais de resíduos diferentes e as três (3) variações de temperaturas, as que mais obtiveram melhores desempenho, em ordem decrescente, são: $15 \%, 20 \%$ e $10 \%$ em peso a $1100^{\circ} \mathrm{C}$. Mas, vale lembrar que todas as séries de temperaturas estão aptas ao uso em revestimento de paredes, objetos planos e utilitários domésticos. Desse modo, para cada produto a seja aplicado o material cabe verificar sua funcionalidade e outros aspectos, de modo a escolher a composição e temperatura de queima adequadas.

\section{AGRADECIMENTOS}

CAPES, CNPq e FAPEMA pelo apoio financeiro e concessão de bolsas.

\section{REFERÊNCIAS}

ASKELAND, D. R., WRIGHT, W. Ciência e engenharia dos materiais. São Paulo: Cengage Learning, 2014.

Associação Brasileira de Normas Técnicas. NBR 13818: Placas cerâmicas para revestimento - especificação e métodos de ensaio Rio de Janeiro, 1997.

ASTM C373-88: Standart Test Method for Water Absortion, Bulk Density, Apparent Porosity and Apparent Specific Gravity of Fired Whiteware Products. West Conshohocken: ASTM International, 2006.

DANTAS, A. P. A. Utilização de resíduos de rochas ornamentais na produção de cerâmica branca. 2008. 96 f. Dissertação (Mestrado em Engenharia Mecânica) Programa de Pós-Graduação em Engenharia Mecânica. Universidade Federal do Rio Grande do Norte. 
GOUVEIA, F. P. Efeito da incorporação de chamote (resíduo cerâmico queimado) em massas cerâmicas para a fabricação de blocos de vedação para o Distrito Federal DF. Um estudo experimental. 2004. 94 f. Dissertação (Mestrado em Estruturas e Construção Civil) - Faculdade de Tecnologia. Universidade de Brasília, Brasília.

GUIMARÃES, K. L. M. Análise da adição de ossos bovinos e rochas ornamentais em massa cerâmica branca para a utilização em processos de conformação. 2015. $117 \mathrm{f}$. Dissertação (Mestrado em Design) - Programa de Pós-Graduação em Design. Universidade Federal do Maranhão, São Luís.

JUNG, M.; CAMISA, I. S.; ALBANAZ, I.; PEREIRA, S. L. S.; CARGNIN, M. Comparativo entre diferentes métodos de determinação da retração linear de placas cerâmicas. In: Revista Técnico Científica (IFSC). 2012, Santa Catarina, Vol.3, №. 1, p. 242-251.

MOTTA, J. F. M., ZANARDO, A., CABRAL JUNIOR, M. As matérias-primas cerâmicas. Parte I: O perfil das principais indústrias cerâmicas e seus Produtos. In: Revista Cerâmica Industrial. São Paulo, 2001. vol 6, no 2, março/abril, p 28-39.

PINHEIRO, B. C. A. Processamento e caracterização de massas cerâmicas incorporadas com o resíduo borra de petróleo encapsulada para a fabricação de grês Porcelanato. 2009. 205 f. Tese (Doutorado em Engenharia e Ciência dos Materiais) - Universidade Estadual do Norte Fluminense Darcy Ribeiro. Centro de Ciência e Tecnologia. Laboratório de Materiais Avançados, Campos dos Goytacazes.

PRADO, A. D. Efeito da incorporação de resíduo industrial (chamote, mármore e granito) para a produção de revestimento cerâmico. 2014. 62 f. Dissertação (Mestrado em Engenharia de Materiais) - Programa de Pós-Graduação em Engenharia dos Materiais. Instituto Federal do Maranhão, São Luís.

PUREZA, J. C. C. Utilização de resíduos industriais de baixa granulometria em massas cerâmicas de argila vermelha: aspectos tecnológicos e ambientais. 2004. 148 f. Dissertação (Mestrado em Engenharia) - Programa de Pós-Graduação em Engenharia de Minas, Metalurgia e de Materiais. Universidade Federal do Rio Grande do Sul, Porto Alegre.

OLIVEIRA, A. P. N. Tecnologia de fabricação de revestimentos cerâmicos. In: Cerâmica Industrial. São Paulo, Vol. 5, № 6, Nov/ Dez, 2000. p. 37-47.

SANTOS, P. S. Ciência e Tecnologia de argilas. São Paulo: Edgard Blücher, 1989.

SOUZA, V.C; SOUZA, J.C.; ROLIM FILHO, J.L. Diagnóstico do setor de rochas ornamentais e de revestimentos do Estado de Pernambuco. Estudos geológicos, Pernambuco, volume 8, 2008.

TALLINI JUNIOR, V. T. Desenvolvimento de novos materiais cerâmicos a partir de lodo de estações de tratamento de água, microesferas de vidro de jateamento, sais de neutralização de ácidos de baterias e areia de fundição. 200983 f. Dissertação (Mestrado em Engenharia e Ciência dos Materiais) - Programa de Pós-Graduação em Engenharia. Universidade Federal do Paraná. Curitiba.

VIEIRA, C. M. F.; FEITOSA, H. S.; MONTEIRO, S. N. Avaliação da secagem de cerâmica vermelha através da Curva de Bigot. In: Revista Cerâmica Industrial. São Paulo, Vol. 8, № 1, 2003. 